\title{
On Making and Reflecting: Anni Albers Theory and Practice-led Research
}

\author{
Larissa Nowicki, Royal College of Art. \\ larissa.nowicki@network.rca.ac.uk
}

\begin{abstract}
The theoretical writing by textile designer and artist, Anni Albers, in her self-authored books On Designing (1961) and On Weaving (1965) provide artists and designers with insights and methods for stimulating resourceful and creative ingenuity. This article examines Albers' modernist theories as they are enacted upon through material and process in a quest to apply Anni Albers' theories as a methodology for practice-led research. While teaching at Black Mountain College from 1933-1949, Albers encouraged her students to begin their creative process by "starting at zero" (Fesci, 1968) therefore this research begins in the same way. Anxieties that arise from making without knowing what something is or what that something may become must be put aside. Trust in the process becomes paramount as creative explorations start from a place of intuitive making which leads the practitioner to more structured and purposeful research leading to new ideas and foresight into future projects.
\end{abstract}

Keywords: Anni Albers, practice-led research, materials, process, methodology 


\section{Introduction}

Artist and self-described maker, Ann Hamilton speaks of cultivating a space where one can dwell in the "not knowing," while making the thing that is yet to be named, trusting it will become well articulated through the practice (Hamilton in conversation with Tippett, 2015). This is the space where artists engage with what Henk Borgdorff refers to as the "nonconceptual content" within art (Borgdorff, 2010, p. 79). Since the emergence of artistic practice as research in the 1970s and 1980s the artist-researcher has appropriated different modes and means of research from established fields in science and humanities in a "bricolage" or do-ityourself approach to create methodologies (Rosengren, 2010 p. 106-107). Although this has afforded the practice-led artist-researcher great freedom to experiment and generate interdisciplinary explorations it does little to authenticate a third paradigm of research founded in creative practice.

This paper examines a case study performed during the onset of $\mathrm{PhD}$ research within the School of Communication at the Royal College of Art. The purpose of this case study was to determine if an established art practice, grounded in the ideology of Anni Albers, could be adapted and applied as a methodology for practice-led research within an academic setting. The artifacts created throughout this phase of research were presented as part of the works in progress exhibition, Intentions: Conversations, Experiences and Knowledge, held in the School of Communication, RCA | White City Place London, which occurred from the 5th-12th of December 2017. The objective was to understand how experimental play with materials and process, in conjunction with reflective analysis performed by an embedded artist as researcher, generates new ways of thinking and questions to be considered. The validity of this researchwhere artist is the researcher performing the making of the art and reflecting upon their activity for the sake of generating new knowledge - is upheld by Donald Schön's analysis of "reflection in action" (Schön, 1983, p. ix) and Brad Haseman's arguments for performative research. If we consider how an artist-researcher "dives in" to see what emerges from their practice before a research question has been defined (Haseman, 2006, cited in Smith \& Dean, 2014, p. 6) and accept this as a fundamental aspect of the artist-researcher's approach, emanating from a natural tendency to make without knowing, we have a starting point from where to begin a multidimensional methodology which is derived from and situated within the creative practice.

Donald Schön's theories of reflection draw upon the work established by the American philosopher and educator John Dewey (Schön, 1992 p.123). Similarly Anni Albers' pedagogy builds upon Dewey's belief in "hands on learning" and "learning by doing" (Fer, 2018 p.68). From 1933-1946 Albers instructed her students at Black Mountain College to initiate creative exploration by "starting at the point of zero." (Fox Weber \& Asbaghi, 1999, pp. 174-175). They were to imagine what it would be like to start something from scratch without reliance upon existing tools, accepted norms, pre-established knowledge, or preconceived notions of what something was supposed to be. Albers' concept of "starting at zero" (Smithsonian Interview, 1968, cited in Coxon, Fer \& Muller-Schareck, 2018) embraced "not knowing" as an advantageous position from which to begin a creative exploration. Unencumbered by established protocols and formulaic strategies, the practitioner is empowered to trust one's own intuition while observing and listening to their materials and learning through process. Under 
the practitioner's hand, processes are tested and parameters become defined. In essence, Anni Albers' teaching method, steeped in Bauhaus ideology as she applied it at Black Mountain College, shares with Schön a belief in the communicative power of material and process. In the early 1980s Schön collaborated with Jeanne Bamberger to study the "process of making things" they arrived at a position much in accordance with Albers' approach. Bamberger and Schön in their article, Learning as Reflective Conversation with Materials: Notes from Work in Progress, concluded "the evolutionary process of making" with materials leads us to see things in different ways ultimately exposing new insights (Bamberger and Schön, 1983).

\section{Building a Case for an Anni Albers Methodology}

This investigation began with a close read of two books written by Anni Albers: Anni Albers: Selected Writings on Design, forward by Brenda Danilowitz (Albers, 2000) and On Weaving, originally published in 1965 , now available as a new expanded edition with afterward by Nicholas Fox Weber and contributions by T'ai Smith and Manuel Cirauqui (Albers, 2017). Through this preliminary research I was able to correlate the ways in which my education and professional practice have been directly informed and influenced by the teachings and theory of Anni Albers, coming to a greater understanding as to why I have arrived at this research trajectory. It is not by coincidence that Anni Albers' theory resonates with my creative convictions. I studied at Rhode Island School of Design, learning from teachers directly connected to Anni Albers. My art and design knowledge is built upon a foundation steeped in Bauhaus culture as propagated by RISD through it's mandatory foundation program and the subsequent studio classes within the Graphic Design department I was enrolled in. "Form follows function" was our maxim.

The education accessible to me at RISD was a direct consequence of worldwide sociopolitical upheaval resulting in the arrival of European modernist masters in the United States prior to the outbreak of World War II. Briony Fer describes Josef and Anni Albers' arrival at Black Mountain College in 1934 as a moment when "the radical experimentation of the Bauhaus foundation course, consisting of a series of practical studies, met the empirical approach of American pragmatism in particularly dynamic ways" (Fer, 2018, p. 65). Today, RISD continues to uphold a commitment to experimental studies similar in philosophy to the Bauhaus' preliminary courses through a mandatory first year studio program. Students are encouraged to draw upon embodied knowledge and material investigations, to think intuitively and deductively, and to develop a critical discourse through studio practice. In keeping with educational progress, RISD has expanded upon its foundation in aesthetic experience by adding additional layers of rigor and criticality to its curriculum. Learning outcomes expected upon completion of the first year foundation course as listed on it's website (risd.edu, 2019) are as follows:

Students completing the first year studio programs will be able to:

- approach art and design with a sustained focus and a rigorous methodology that includes the ability to construct a question for inquiry 
- demonstrate the ability to critically analyze their studio work and the work of others within personal, theoretical, cultural, social and historical contexts

- discuss and implement formal design terms and concepts, and understand the complexity of debate inherent in their application

- recognize that their sensibilities influence their creative processes and that these are important aspects to consider in their choice of a fine art or design discipline

These learning outcomes (http://www.risd.edu/academics/experimental-and-foundationstudies/first-year/) reveal how RISD have positioned research in tandem with a studio practice at the forefront of a visual arts educational experience. Research terminology is ubiquitous in the vocabulary used to articulate expectations: "methodology," "question of inquiry," "critically analyze," "contexts," “creative processes," "discipline." Undergraduate students are indoctrinated in research thinking before they have decided upon a concentration in either fine art or design. This is not to say emphasis has been taken away from creative practice and aesthetics. Rather, it evidences a commitment to elevating the status and rigorous nature of creative practice in order to position it on the cutting edge of learning. John Maeda, President of RISD from 2008-2013, promoted the change of STEM (Science, Technology, Engineering, Math) to STEAM (adding Art to the acronym) driven by his belief that "art and design have critical roles to play in innovation in this next century, much like science and technology did in the last" (Maeda in Somerson \& Hermano, pp. 8-9.) Anni Albers began incorporating experimental methods into her textile practice at the Bauhaus in Germany, developed them into teaching methods while at Black Mountain College in North Carolina and later communicated them through her lectures at Yale University and in published texts. It would seem creative disciplines are primed to move beyond using social sciences to validate their contribute to research in academia (Sullivan in Smith \& Dean, 2014, p.46). We are long overdue in recognizing and naming the research methods innate to artists and designers that have continuously been passed down from one generation to the next for over 100 years.

\section{Starting at Zero as a Method for Initiating Practice-led Research within Art and Design Disciplines}

After evaluating Albers' written texts I have formulated a systematic approach to making with materials. This system is comprised of a series of interrelated phases. Each phase builds upon findings derived from the previous phase. As a framework, this system operates to move an exploration forward into something more defined and ultimately realized. However, within each phase there is the space for non-linear, more circuitous (and sometimes messy) experimentations and reflection. Proposed categories and keywords for each phase are based on the essential aspects of the creative process according to Albers ("Work with Material" 1938 "Material as Metaphor" 1947, and "Design Anonymous and Timeless" 1947 in Albers, 2000. "Designing as Visual Organization" in Albers, 2017) and are as follows:

- Experimental Play (beginning, without limits, learn by doing, haptic)

- Focused Material Exploration (listen, collaborate, form, surface, texture)

- Design Processes (ecological, conservation, without artifice, timeless, modern)

- Tools and Technology (purposeful, functional, continuity, juxtaposition, ingenuity) 
- Purposes and Production (foresight, communicative, withstanding, interdisciplinary)

- Possibility for Transcendence (radical, beauty, transformative, art, metaphysical)

- Contextualization (reflection, possibilities, discourse, theory, adaptation)

\section{Case Study: This is White City}

Practice:

I understand how Albers' texts serve as theoretical underpinning for my art making process. My aim in this situation was to determine how Albers' philosophy in regards to making within a realm of not knowing could lead me to generate new ideas and inquiries for research purposes. More specifically, how could this initial phase of "experimental play" make apparent the motivations and predicaments underlying or leading to research inquiries? For the initial exploration I went "back to zero" in my fine art practice. I attempted to create the sense of being an amateur by stepping outside my comfort zone and engaging with non-familiar processes. I situated my activities within an environment I was not accustomed to working in. I chose materials and methods that I had not engaged with as part of my established practice (charcoal, graphite, stone rubbing, and pavement stones set within sidewalks.) I approached the activity with no preconceived notions of what I would encounter or achieve in the making. Without hesitation I dove into my first investigation with an expectation that new ways of seeing would happen instantaneously, occurring simultaneously with the art making process.



Figure 1: pavement stone rubbing in process, graphite on paper 
- Location: White City Tube station in west London, working there on three different days at different times to understand how changes in the time of day affected my experience and the outcome of the experiment. (Saturday 1pm-5pm, Sunday $8 \mathrm{am}-1 \mathrm{pm}$, and Tuesday $10 \mathrm{am}-2 \mathrm{pm})$

- Materials: Experimented with different drawing materials and papers on site, quickly finding that pressed graphite 4B and smooth finish white cartridge paper in a medium weight gave me the best results (as opposed to charcoal and premium art paper in a heavier weight and different colors).

- Process: Climate and sidewalk traffic determined when and where I could set up, which pavement stones I could work from, and the duration and density of each rubbing. I sat on the ground and worked directly on top of the pavement stones. On average I completed ten A1 sized rubbings in varying densities of graphite imprints per session. Sessions tended to last 4-5 hours.

- Documentation: In addition to each completed street rubbing I documented the making of the artwork and the location using iPhone photography.

\section{Observations:}

After each session I had an aesthetically pleasing set of "drawings." Away from the original pavement stones it was not clear what these drawings depicted. They appeared to be abstract in nature. In studio, while contemplating these works of art as drawings, questions came to the forefront. What purpose did these drawings serve? What did they communicate or expose in relation to my research? How could I translate the materiality and the process of the experiment into findings relevant to this research? It became evident other methods would need to be implemented to document and reflect upon this initial practice-based exploration in order to generate better reference material for research purposes.

In order to re-frame the exploration in relation to performing research I utilized an additional method to examine the process of making art. From memory I wrote my subjective observations of the event as narrative vignettes in the first person. These vignettes told the story of what happened in the environment I occupied while engaged in the practice. Some people approached me, some watched what I was doing silently, some asked direct questions, and others walked by nearly stepping on me. While I was working I did not stop my activity to notate any of this. After the event, writing each encounter as a story with descriptions of the people, I was able to document other aspects of the event and I became aware of an alternative aspect to this research. The narrative writing process moved at a slower pace allowing for me to be more subjective and creative in the construction of my documentation compared to simply filming of the event or making a non-rehearsed voice recording. I could choose my point of view and linger on certain events for deeper reflection. The constructed narrative exposed insights and new ways of seeing how practice can operate within a research context. 


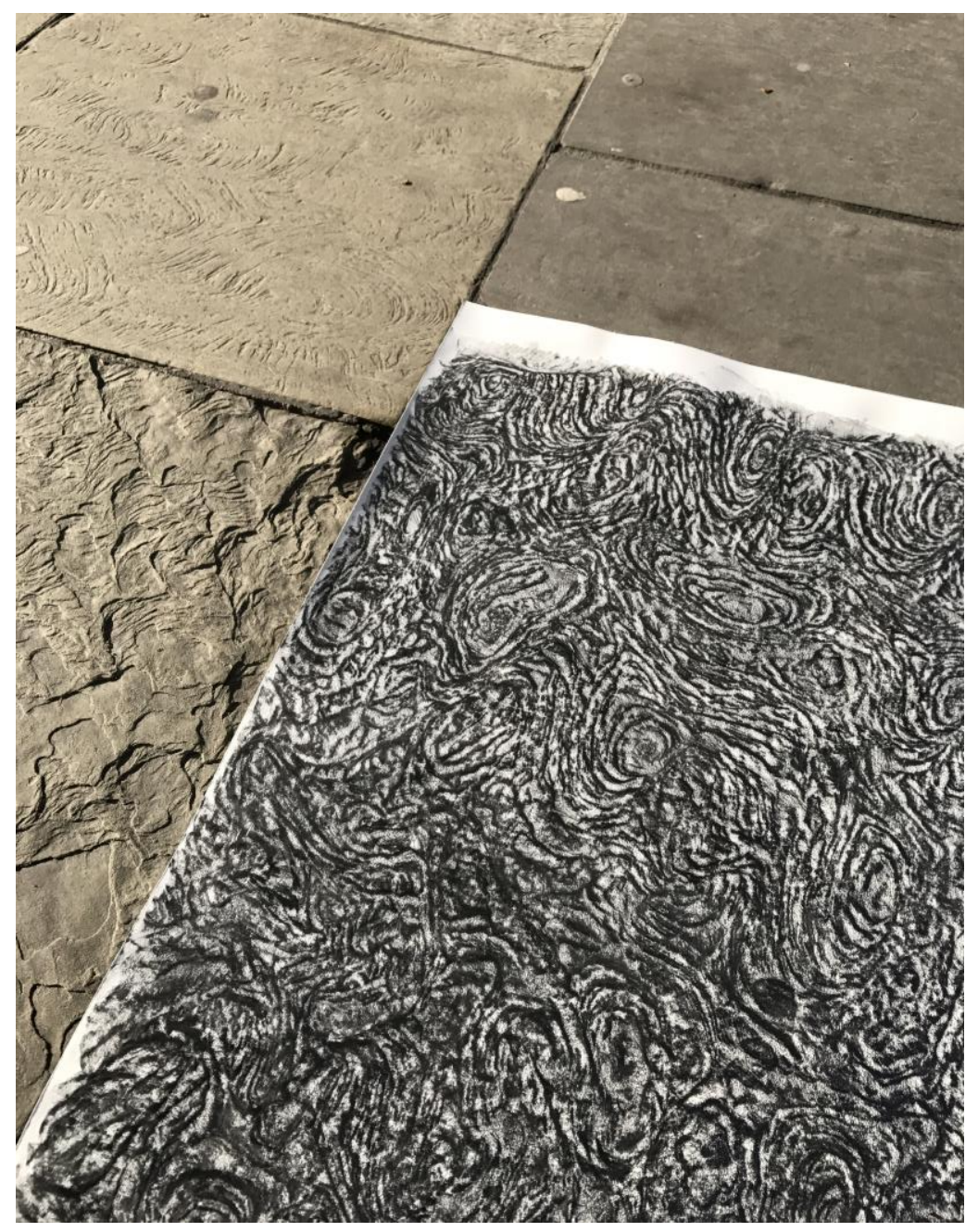

Figure 2: pavement stone rubbing complete, graphite on paper

The following narrative observations were written after the first investigative session, which occurred on a Sunday morning. In remembering my encounters with various members of the local community the paradox and insight of the experiment in "White City" became apparent. White City is more than what is indicated by the location's name. It is a multi-cultural neighborhood where people from all over the world coexist in a modern-day global community. It is a place where cultures overlap and blend into new ones. The following narratives make this evident.

I. I've been unsure how to move forward with my research, with the written words I have to compose. I've found information. Loads of it churns through my mind threatening to overflow incoherently. It resides pressurized, straining against the interior side of my ribcage. I know what I have to do. I have to make. Something. Anything. I need lose myself in a rhythm that arises from the focus of doing. I set the alarm for seven a.m. and let myself out early. Empty buses glide by smoothly without excess weight to bear. The 
only other people a lie-in. On the street I spread out the first sheet of paper and kneel down to begin. It's Sunday morning. I have a fleeting memory of church, St. Michaels. Today I put faith in the art. I wonder where that thought came from-Anni Albers. Art was her constant with transformative power equal to philosophy, science, and religion. I hold a chunky stick of graphite between my fingers and make the first sweeping gesture creating a mark across the blank page.

II. The texture of the pavement stone emerges as I rub the graphite against the surface of the paper. Using long broad strokes and circular motions I cover the entire sheet. Radiating from the center I build up layer upon layerisepimoving towards the four edges of the paper with increased pressure. The interwoven fibers that form the paper are compressed between two unyielding surfaces. The graphite transposes decades of swirling erosion embedded in the stone. Morning sunlight speeds the evaporation of puddles from the previous day's rain but I still feel a dampness seeping through my clothes to pull the warmth out of my skin. I don't mind the discomfort. I'm hypnotized by the patterns taking shape on the paper. An old man stops. He asks if I will sell these drawings. I'm surprised by the question. Why would anyone buy these rough experiments? These are not for sale. This is just the beginning I tell him. The uniqueness of these particular pavement stones and their beauty inspired me and drew me here. He looks closely at the ground and agrees. They are beautiful.

III. I've never been a plein air artist. I don't like to make in the proximity of iscepiothers but I'm challenging myself to apply Anni Albers' theory to my practice. She says begin as an amateur, explore with a sense of adventure into unknown territories and so here I am. It took me a week to commit to this exercise sêpiand purchase a medium I hadn't used in so long it would feel new to me. Today, the ninth day, I muster up courage to spread these supplies out on the sidewalk and begin my work hoping no one bothers me. At first no one even takes notice of me. Foot traffic on the sidewalk increases while I move around from one stone to the next trying to stay out of people's way. They don'tisepiavoid me. They look over my shoulder to see what I'm doing but don't linger long enough to converse. I have my headphones on but the music has stopped and I can hear everything around me. Across the street a small child looks down from a second floor window. She stands with her face pressed against the glass watching intently. She catches my attention by banging on the window with her little fist until I look up. Now we have a game. She knocks - I see her and wave. She drops out of sight until I go back to work. I imagine fromisper vantage point she sees patterns grow across the page as if by magic. Directed by the motions of a graphite wand.

IV. The sun reaches a higher point in the sky and spills more light across of stones. The morning is almost over. I'm engulfed in a heavily perfumed sea of black that parts and rushes closely around the islandispi I've created on the sidewalk. Behind me the edge of a long robe brushes across my exposed ankles while more robes drag loose crumbs of graphite from the surface of the paper in front of me blurring and softening the hard edges of my drawings. I look up and see the last one in a group of Muslim women 
hesitate. My eyes connect with hers and despite most of her face being covered; I can sense a friendly inquisitiveness about her. Definitely curious, isteps ishe lingers for a brief moment, observing me crouching on the dirty sidewalk. I'm nearly out of paper and I need a break. Using my arms to push myselfiseppoff the ground, I step one foot forward gingerly. A teenage girl veers towards me unexpectedly. "Are you alright?" She asks with concern. My feet tingle with pins and needles and my joints are stiff and cold. I realize she thinks I've fallen and I'm hurt. My laugh reassures her I'm fine. She notices my fingers covered in graphite gleaming as black as hers. This girl doesn't missișẸpa beat and asks me to direct her to the nearest art supply store.

V. I move my supplies out from under the shadow of a building and chase the sun to a new pavement stone. With the lead worn down to a sliver in my fingers, I work with vigor on the last three sheets trying to make them dense with detail. Almost done. I lean back on my heels to pause and take a look. A man stops and stands beside me also examining the work. He's curious and asks a few questions and seems pleased with the answers I provide. He delivers his review in a deep Eastern European accent, "Very Good. Very Very Good." We fall silent in the act of looking again. A shadow falling over the work creeps up and over my kneecaps. Before us stands a man large enough to eclipse the sun. "She's an artist," says the Eastern European unable to contain his knowledge, "It's very nice, no?!" The giant gentleman nods in agreement. He tells me he's walked past five times this morning unnoticed by me. He wants to understand more and know what kind of art I'm making. I explain. He listens patiently as I find my way around my words, how I study at the Royal College of Art and this is the route I walk to my studio. We talk about inspiration and beginnings, starting points. These pavement stones are my new way. He says welcome. This is the first gesture, a mark to carry me forward to the next movement.

Output:

Within the first term of this $\mathrm{PhD}$ research, the Communication Department at the RCA presented a work in progress exhibition-making public the early stages of practice-led research. This was an opportunity to present my early findings and further test an Anni Albers methodology. I continued in my attempt to operate from outside of my established experience in relation to art and exhibitions in order to instigate new ways of seeing, thinking, and learning. I approached the work in progress exhibition as a venue to reveal the graphite drawings created through and for research. By this stage I had come to view them as artifacts rather than art. For the purpose of this exhibition I had decided they were not to be framed or presented in any way that would signify the work had any monetary value or cultural significance as fine art. I spread the unfixed graphite drawings across the floor of the studio to view them as a group (and to avoid transferring any of the loose graphite onto my clean desktop). In that moment it occurred to me to present them exactly as I was looking at them-on the floor, where anyone could walk on as they would walk upon a city sidewalk.

The gallery space was equally divided amongst the participating students. My research artifacts were spread across the floor, covering most of my section. I arranged them in a 
"running bond pattern" similar to the actual sidewalk outside. Gallery visitors walked around my work to avoid stepping on what they perceived to be finished works of art. They asked what the abstract "drawings" represented. To entice visitors to walk across the work I created postcards printed with my narrative observations and placed them in the center of the piece. Even though the cards were meant to entice visitors to walk across the drawn surface most visitors preferred to remain outside the perimeter of the installation. Visitors were overheard saying it felt wrong to be standing on the work, that they did not want to damage it, that it was too nice to walk on. It was not until enough people had walked across the paper and smeared the graphite with their footsteps, that foot traffic increased across and postcards were picked up to learn more about the research project. With printed cards in hand visitors read the text, looked down at the swirling patterns beneath their feet, and appeared to recognize the link to the outside world visible through the gallery windows.

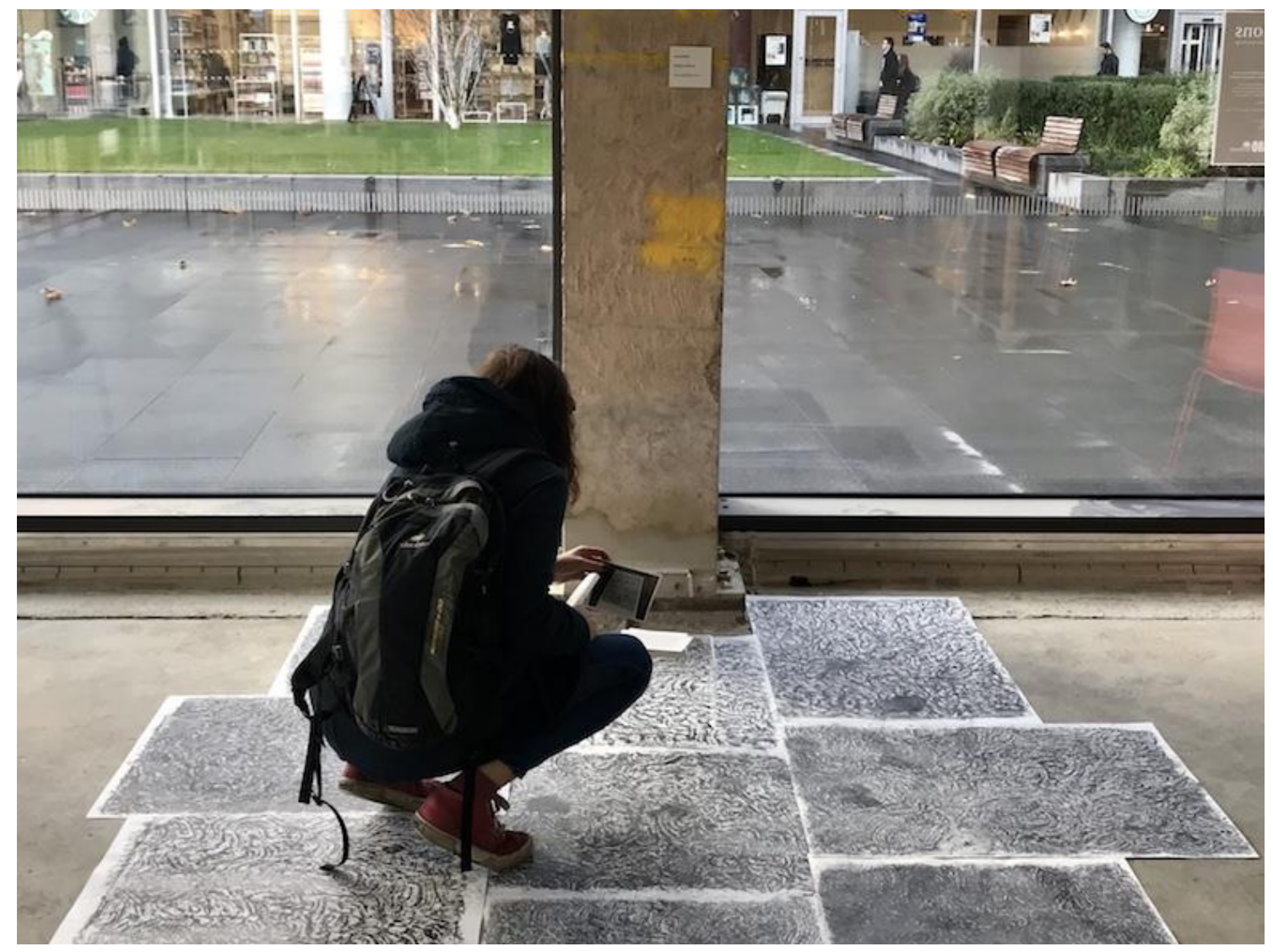

Figure 3: This is White City work in progress exhibition

\section{Reflection:}

In the end, this practice-led investigation provided me with a variety of thought provoking results the most important being an insight into the way one approaches and conceptualizes 
practice within research. Fundamentally I see making with materials as an opportunity to orchestrate an event by which to generate data. The work of art produced during the practice is becomes artifact generated by practice as a research method. It may instigate and elicit further responses as the research continues. The 'practice' must be considered beyond the initial parameters of making something (i.e. a work of art) and should take into account the generative nature of the entire experience from a more whole as it persists and evolves, building upon itself.

The gallery visitor was able to visually experience my research while actively participating and making an impact upon it. Engagement with the work in a bodily sense (by walking across it) gave the gallery visitors an immediate experience that shifted their perspective. The work became something other than an off-limit artwork in the milieu of a traditional gallery setting. A visible trace of this interaction is left in their footprints upon the surface of the unfixed graphite. This two-fold experience for the visitor provided me with additional insights for my research. The visitor occupying two roles becomes analogous to the duality of my position as the artistresearcher. They passively observed from the perimeter of the installation, and actively participated through their footsteps across the surface of the artifact. To know more they had to "do" something and their movement brought them closer to that knowledge. It was an experiment in understanding how materials and process within a fine art practice can instigate new ways of seeing, looking, and thinking not only for the artist-researcher but also for the audience who encounters the event or the artifacts of the research. In this case the artifact was not static. It was mutable and in the exhibition it continued to reflect the movement of different people, becoming transforming beneath their feet as their experience expanded.

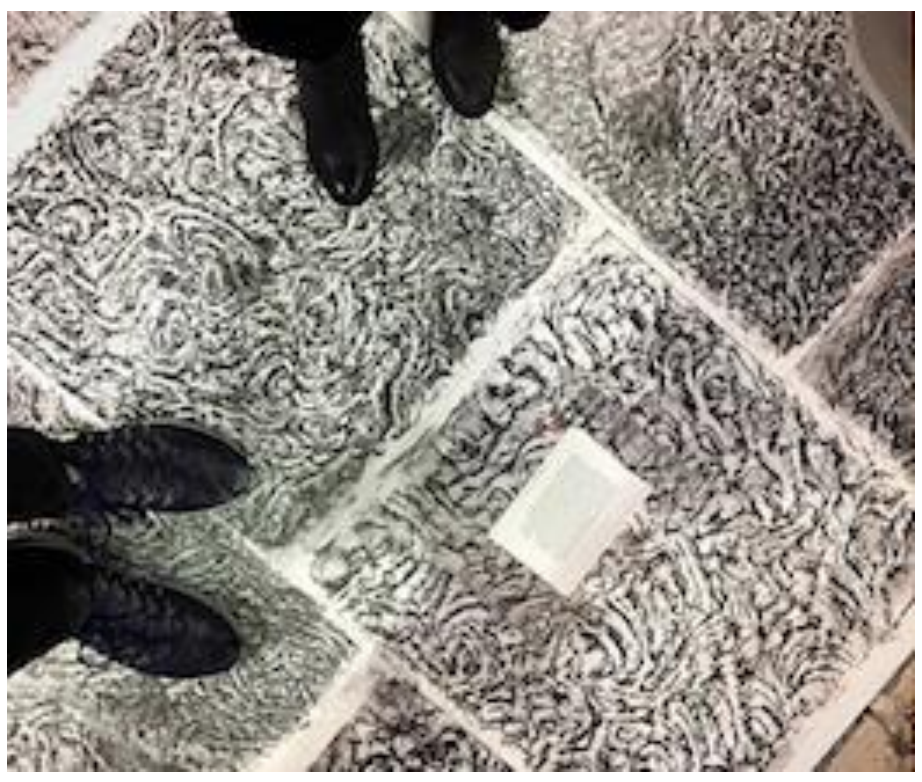

Figure 4: This is White City 


\section{Conclusion}

This was a case study to test developing methodology. These activities are positioned within the initial phase of a research project. In this early state I am determined to adapt Anni Albers' theory for creative practice into a methodology that commences in the "not knowing" before leading the artist-researcher to a deeper awareness of their research concerns. An approach to research based on Anni Albers' theory supports the articulation of a well-formulated research question after early phases of creative exploration have been instigated. This would change the conventional practice of stating a research question at the onset of $\mathrm{PhD}$ research to later stages of the investigation and align with Carole Gray's assertion that researchers' problems emerge over time and their research questions change throughout ongoing practice (Haseman \& Mafe, in Smith \& Dean, 2014, p.214).

Throughout her career, Anni Albers looked to the past and the textile traditions of the ancient Peruvians to affect the future of textiles and to break down creative and social boundaries. She deconstructed prized samples of their work to learn firsthand from their mastery. (Troy, 2002, p. 145) and used that knowledge to disrupt the status quo. In 1990 she received an honorary doctorate from the Royal College of Art and has been cited by Anne Hamilton (Smith in the NYT, 2012) and countless other artists, designers and makers as a major influence. Contemporary artist-researchers only need to look back at recent art and design history of the $20^{\text {th }}$ Century in order to build proprietary methodologies. Anni Albers' expertise is on prominent display. Her modernist theories informed all her activities as a student, teacher, designer and artist. She was in constant communication across multiple disciplines through her weaving and printmaking practices, as well as through her teaching and theoretical essays. Her pedagogy entwined with the history of the Black Mountain College experiment in the 1940s further broke down barriers between disciplines (Harris, pp. 16-17, in exhibition catalog Starting at Zero: Black Mountain College, 1933-57.) The BMC summer sessions made up of a multidisciplinary assortment of attendees living and working in an environment of collaboration foreshadows the eventual emergence of post-modern academic research within creative practice. Today Anni Albers' legacy is available to validate the strength of making and reflecting in creative practice and to support the establishment of a third paradigm of research, founded within the creative disciplines.

Today we realize space in both real (tangible) and virtual (intangible) planes. Creative industries and practitioners operate in both realms. Any new methodologies need to have the capacity to function across a variety of project scopes from handmade making to technologically advance virtual simulations. Even though society presses forward and the world becomes ever more technologically advanced it is still vital for creative practitioners to be able to use their embodied knowledge as a means to learn and communicate (Wilson in Somerson \& Hermano, 2013, p.16). I believe artist-researchers do not need to appropriate methodologies from other disciplines. Anni Albers' masterful legacy of process orientated inquiry and reflection exists within the creative domain and is accessible though concise theoretical texts if we choose to adopt it for the purposes of practice-led research. 


\section{Acknowledgements}

Teal Triggs and Tom Simmons from the School of Communication, RCA. Professor and RCA fellow researcher, Cristina Portugal. All the post-graduate research students within the School of Communication, RCA who organized and made possible Intention: Conversations, Experiences and Knowledge-Research Work in Progress.

\section{References}

ALBERS, A. On Weaving. CT: The Josef and Anni Albers Foundation, 2017.

ALBERS, A.; DANILOWITZ, B. Anni Albers: Selected Writings on Design. Hanover: University Press of New England, 2000.

COXON, A.; FER, B.; MULLER-SCHARECK, M. Anni Albers, London: Tate Publishing, 2018

DEWEY, J. "Experience and Thinking," in Democracy and Education: an Introduction to the Philosophy of Education. New York: The Free Press, pp 139-151

FER, B. "Black Mountain College Exercises," in Coxon, A.; Fer, B.; Muller-Schareck, M. Anni Albers. London: Tate Publishing, 2018

FESCI, S. Oral History Archives of American Art. Smithsonian, 5 Jul. 1968

FOX WEBER, N.; TABATABAI ASBAGHI, P. Anni Albers. New York: Solomon Guggenheim Foundation, 1999

HASEMAN, B. "Rupture and Recognition: Identifying the Performative Research Paradigm," in Barret and Bolt, eds. Practice as Research: Approaches to Creative Arts Enquiry. London: IB Tauris, 2007

MOLESWORTH, H.; ERICKSON, R. Leap Before You Look: Black Mountain College, 1933-1957. Boston, MA: Institute of Contemporary Art/Boston, 2015.

ROSENGREN, M. "Art + Research $\neq$ Artistic Research," in Caduff, C.; Siegenthaler, F.; Walchli, T.; eds. Art and Artistic Research. Switzerland: Verlag Scheidegger \& Speiss AG, 2010

SMITH, H.; Dean R. T. Practice-led Research, Research-led Practice in the Creative Arts. Edinburgh: Edinburgh University Press, 2014

SMITH, R. "The Audience as Movement," The New York Times, 6 Dec. 2012. Accessed 28 Aug. 2018, https://www.nytimes.com/2012/12/07/arts/design/ann-hamilton-at-the-parkavenue-armory.html

SMITH, T. Bauhaus Weaving Theory: From Feminine Craft to Mode of Design. Minneapolis: U of Minnesota Press, 2014.

SCHON, D. A. The Reflective Practitioner: How Professionals Think in Action. New York: Basic Books, 1983.

SCHON, D. A. "The Theory of Inquiry: Dewey's Legacy to Education," Curriculum Inquiry. 1992, vol. 22, no 2, pp. 119-39.

Somerson, R.; Hermano, M. L. The Art of Critical Making, Rhode Island School of Design 
on Creative Practice. Hoboken, NJ: Rhode Island School of Design, 2013

TIPPETT, K. "Making and the Spaces We Share." The On Being Podcast. 19 Nov. 2015, Accessed 15 Jun. 2018, https://onbeing.org/programs/ann-hamilton-making-and-the-spaceswe-share/

TRIGGS, T.; SIMMONS, T.; CANDELA, E. Intentions: Conversations, Experiences and Knowledge. London: Royal College of Art, 2017.

TROY, V. G. Anni Albers and Ancient American Textiles: From Bauhaus to Black Mountain. UK: Ashgate Publishers, Ltd, 2002.

\begin{abstract}
About the author $\mathbb{I}$
Larissa Nowicki's art practice derives from her experience as a book designer. She uses pages from books as a medium — shredding and weaving them into tapestries. Her work can be found in public and private collections worldwide. She is a graduate of the Royal College of Art and Rhode Island School of Design. Currently she is a PhD candidate within the School of Communication at the Royal College of Art.

E-mail: larissa.nowicki@network.rca.ac.uk
\end{abstract}

